\title{
From Bakhtin to See the Co-construction of EFL Adult Learners' Utterances
}

\author{
Chingyi Tseng ${ }^{1} \&$ Keun $\operatorname{Huh}^{2}$ \\ ${ }^{1}$ Department of Applied English, Shih-Chien University Kaohsiung Campus, Kaohsiung, Taiwan \\ 2 Department of English Language and Literature, Hannam University, Daejeon, Korea \\ Correspondence: Keun Huh, Department of English Language and Literature, Hannam University, Daejeon, \\ 306-791, Korea. Tel: 82-42-629-7381. E-mail: keun@hnu.kr
}

Received: April 1, 2016 Accepted: May 2, 2016 Online Published: May 3, 2016

doi: 10.5539/elt.v9n6p42 URL: http://dx.doi.org/10.5539/elt.v9n6p42

\begin{abstract}
The purposes of this study were to explore the effect of dialogic activities on EFL students' utterances development by engaging with others, as well as the students' perceptions in the dialogic learning environment. The theoretical framework guiding this inquiry consists of the on-site lecture from the instructor and voice board feedback from the peers and the instructor based on the dialogical theory of language concepts from Bakhtin's dialogism which emphasizes a social and interactive situation of foreign language learning by engaging with others. In this study, we cover multiple data sources that give us an overview of students' interaction in the dialogic activities: the questionnaire of voice board interactions, students' interviews, and speaking tests. The results showed, on the whole, English language learners actually developed some kind of utterances by engaging their own and others. They transformed others' utterances in the oral interaction for their own use in the Asynchronous Computer Mediated Communication (ACMC) environment. Additionally, the learners perceived the voice board activities helpful for the development of their speaking abilities, while the learners' perceptions are mediated through the dialogical activities in which the learners are engaged in.
\end{abstract}

Keywords: Bakhtin's dialogism, utterances, ACMC, speech communication, oral discourse

\section{Introduction}

Van Lier (2000) described that language learning as the result of the relationship among learners and the learning environment, which hinges on the connection between the cognitive and social process. From a sociocultural theoretical perspective, learning a foreign language is a cognitive experience, as well as an interactive, social experience (e.g., Mercer, 1995; Vygotsky, 1978). Establishing specific conditions can facilitate meaningful dialogue and a deeper understanding of the language, particularly with regard to speech communication. This is especially true when dialogue serves as the major mediating source in the cognitive development of English as Foreign Language (EFL) students (Dufva \& Alanen, 2005). Learning a language means committing to the creation of a dialogic learning environment in order students to expand their knowledge and engage with others in the target language. Unfortunately, the application of new vocabulary and grammatical concepts can be challenging (Bygate, 2006). Furthermore, EFL students' seldom have the same opportunities to learn phrases or interact with others that native speakers enjoy. The resulting lack of speech communication can greatly limit the degree to which EFL students engage in the development of cogent thoughts or the organization of ideas in English. In this study, we review the relationship between the theoretical framework presented by Bakhtin and the voice board tool is called voxopop. We also examine the factors affecting how EFL students accumulate language forms and the implications that this has on the learning of for foreign language.

\subsection{Literature Review}

The following review explores the existing literature dealing with Bakhtin's conception of dialogism, and how it manifests in the development of speech communication in on-site and voice-board classroom settings.

\subsubsection{Bakhtin and the Utterances of Language Learners}

In his writing regarding dialogue, Bakhtin specifically focused on utterances. Dialogues demonstrate the importance of utterances through the creation of new meaning. By making utterances, EFL students begin to understand language and react within the dialogue situation. An utterance is a form of speech communication 
(long or short) corresponding to a typical situation involving oral communication. Examples of utterances are as follows: the interaction of everyday conversation when asking a question and responding with an answer, the style of speaking when giving a thesis, and its supporting ideas. According to Bakhtin, language learners are interested in listening to others speak as well as responding and anticipating the responses of others in their learning community and this fundamental dialogism is the way to understand the co-construction of utterances (Hosenfeld, 2006). Consequently, the EFL learner depends on active involvement in a situation and engagement with others gives learners the opportunity to themselves as speaking like a native speaker and constructing new meaning (Pavlenok \& Lantolf, 2000). Due to the development of oral ability involves the assimilation of target vocabulary and grammatical rules through memorization and dictation. The learner then seeks to understand the significance of the conversation in order to add new meaning in their role as an interlocutor. Utterances of production involve attempts by the speaker to express meaning (Collings, 2007; Valle \& Aponte, 2002; Wertsch, Hagstrom \& Kikas, 1995). For example, when a language learner has accumulated a new vocabulary word but has not had the chance to employ it, the experience of reading a text or talking with someone can help to form a link between the new word and a real-life experience. When learners listen to many voices and have interactions in their new language, they are able to make a transformation to generalizing use of the language. The process of making utterances has a critical impact on the development of speech communication ability (Dufva, 2006).

\subsubsection{Bakhtin and Surrounding Rapport}

Bakhtin claimed that foreign languages are learned through the various situations encountered in daily life, such as interactions with peers or instructors. This assertion is supported by the observation that learners tend to accumulate vocabulary while talking with others or reading from a textbook. Learners tend to repeat the words and implement the grammatical forms they hear on an on-going basis (Alanen, 2006). Thus, a failure to activate new language form within the context of a discussion or existing background knowledge can prevent the formation of utterance by language learners (Wertsch, Hagstrom, \& Kikas, 1995). This means that language learning is a combination of one's experiences in social interactions and one's practice in the implementation of specific language skills. The creation of language involves the active development of the learner in the proximal context of interaction with others through a transfer of knowledge from individuals who know more to learners, who know less. Therefore, we believe language learning itself provides more opportunities for learners to develop utterances thereby acquiring new forms and vocabulary.

\subsubsection{Bakhtin and Voice Boards}

Developing the skills required for oral communication in the target language is the ultimate goal in learning a foreign language. According to Bygate (2006), oral training in practice often tends to take the form of speaking freely or creative talking. However, EFL students cannot simply be encouraged to speak, but rather they must be encouraged to structure their utterances in a logical and meaningful way. This requires that language learners comprehend the meaning of the words or phrases they use. However, in an EFL learning environment, students have very little opportunity to plan or check the organization of content. When studying an article, learners have time to recall and comprehend the meaning of the text; however, speaking situation proceed too quickly to allow students to evaluate every expression they encounter or try out throughout a given conversation (Dufva, 2006).

Researchers in the application of Asynchronous Computer Mediated Communication (ACMC) to foreign language acquisition have investigated the use of voice boards to enhance speech communication by motivating students and helping them to develop confidence. Due to voice boards allows users to record audio directly to the website where each recording is displayed in a sequential order, Hsu, Wang, and Comac (2008) discovered that voice boards could enhance the speaking ability of English Language Learners (ELLs) studying in the U.S. and develop their confidence in using English. Students reported that the feedback provided by a teacher was useful and that the voice boards could be adjusted to their individual pace. Voice boards provide a positive environment in which learners are able to anticipate the response provided by their peers. Sun (2009) evaluated the use of voice boards by university level EFL students in Taiwan. They obtained positive results in the promotion of speaking performance as well as the acquisition of new words and phrases. Students in a voice board environment feel less pressure and are more willing to speak. Song (2009) reported that voice boards improve speaking performance by enhancing one's willingness to use the language by providing a supportive structure while providing a mechanism through which one's performance can be evaluated. The contents of discussions can also be reviewed without time constraints or social pressure, thereby helping to reduce the fear of making mistakes (Özdener \& Satar, 2008; Baralt \& Gurzynski-Weiss, 2011).

Learners in a voice board environment are more willing to speak up and participate in activities. In an EFL context, Pop et al. (2011) pointed out the importance of voice board tools during activities claimed that students 
excited and proud to see themselves on the Internet. Voice board promotes a more interactive learning environment without time and space limitation. They are also easily implemented in the classroom to promote the development of speaking performance (Hsu et al., 2008). This approach gives learners sufficient time to think about input and ready their response. Numerous voice boards have been established for language learning; however, little research has been performed on the perceptions of learners with regard to the process of learning new utterances in a dialogical language learning environment. Therefore, creating a dialogical environment integrating voice board use in the classroom can increase learners' willingness to communicate to construct utterances.

In this section, we described the process of learning and generating utterances in a dialogical learning environment. We also investigate the impact of voice board tools in the development of speech communication skills by EFL students. According to Tallon (2009), learning a language is a process of interacting with an interlocutor; the reshaping and re-construction of social interactions by asking and responding to questions for the resolution of a knowledge gap or other such difficulty. In a dialogical learning environment, language learners have the time they need to decipher questions and formulate an oral response. Therefore, this study uses Bakhtin's dialogism to examine by explaining the utterances of development within a dialogical learning environment. Such examination may result in suggestions for improving language learning instruction.

\section{Method}

Our aim in this study was to explore the effect of oral dialogic activities on student utterances and their perceptions of the activities performed in a dialogical learning environment. In this study, the course material was delivered in two ways: through on-site course and through the use of the voice board tool (http://www.voxopop.com/) a platform on which the researcher (instructor) and participants could engage outside of classroom. As mentioned previously, the voice board tool, voxopop, allows users to record audio directly on the website with each recording displayed sequentially. Throughout the course, the instructor used a textbook as the main source for lecturing and course preparation. The instructor also allowed students with the opportunity to apply oral strategies from the textbook in class in order to help them to use the strategies on the voxopop voice board. For instance, the instructor demonstrated various strategies, such as asking critical questions or making interjections to point out the weaknesses in the others judgement. These enabled participants to be aware of their impediments and revise their language while achieving continuous learning and using new utterances. The instructor and participants talked with each other using voxopop as if in conversational situations, thereby making them more comfortable in the delivery of monologues outside of the class. Participants were asked to record a post in order to obtain points for homework. Initially, the participants published weekly recordings of their arguments as well as examples of oral reading from the textbook. All of arguments were associated with topics dealt with in the on-site class. For example, the topic of tourism could lead to the voice board homework in which participants are asked to respond to the following statements: 1) Tourism really helps economically deprived areas; 2) Developing new transport infrastructure, such as roads or cheap flight services, helps bring tourism to isolated areas. Each participant would respond to one statement and provide reasoned justification for their agreement or disagreement. Participants asked two questions regarding the argument of others and responded to two questions about their own arguments. Finally, the participants would record their final thoughts as concluding statement.

The questionnaire, interviews, in-class observations, and voxopop experience surveys were triangulated to ensure consistency of evidence across various sources of data. The process of triangulation provided a more comprehensive understanding of the interaction between participants and instructor in the classroom from this course. The data sources used in this study included the following: (a) oral reading and speaking perception questionnaire, (b) common speaking test, (c) surveys for the evaluation of voxopop with regard to oral reading and opinion sharing, (d) observation of in-class discussions, and (e) open-ended interviews.

The purpose of this qualitative study was to provide the process description of EFL college students' transform new utterance and explanation of the EFL college students' perception of learning utterances by examining the Bakhtin's dialogism. The following two research questions were adopted for this study:

1). How do oral dialogic activities affect EFL college students with regard to the transformation of utterances they make in a dialogical learning environment?

2). How do EFL college students perceived the effectiveness of oral dialogical activities with regard to their development in learning utterances? 


\section{Results}

Bakhtin's framework of dialogism was used as a vehicle to explore the process of learning utterances with others through dialogical learning environment. For ease of reporting, the organization of the major findings is based on specific research questions.

Research Question 1: How do oral dialogic activities affect EFL college students with regard to the transformation of utterances they make in a dialogical learning environment?

\subsection{Description of Individuals - Johnson's Co-consturction of Utterances}

\subsubsection{On-site Class Dialogue: Johnson}

During the on-site class, the instructor had participants ask their partner that they are not familiar with and using the words and discussion strategies outlined in the textbook. In the first semester, Johnson partnered with a classmate and asked question that he had known previously. In the second semester, Johnson asked questions but, continued to address participants which whom he was already acquainted. Nevertheless, he was required to address an unfamiliar student in order to complete the class discussion requirements. In recalling his experience asking questions of someone he didn't know, Johnson responded as follow: "I know that I had to ask stranger's questions to someone, but at first I asked only the people around me. Eventually, addressing to a stranger forced me to consider the ideas and opinions of others, which really expanded my knowledge and words that I could use". Despite the fact that Johnson did not use the new words of the textbook, he came to realize the benefits of asking questions to persons he didn't know would help him to generate new ideas and knowledge.

\subsubsection{Voxopop Dialogue: Johnson}

At the start of the voxopop dialogical activities, Johnson had difficulty uploading the audio file; however, he enjoyed interacting with other classmates in English. During the voxopop activity, Johnson reused the word "cure" five times and "illness" four times, both of which were listed in the textbook. The following quote was selected from Johnson's voxopop assignment for Unit 7 from the initial to final statement discussion practice assignment to claim his opinion:

1). I agree with the statement, "Using...acupuncture is a much gentler way of...", because it can 'cure' the injury from the accident... (Excerpted from the initial statement)

2). ...If I want to reduce or 'cure' my headache...it's the best medicine to 'cure' my headache...I think music is a wonderful way to 'cure' many other 'illness'. (Excerpted from his reply to a question)

3). ...This was my first time to try another treatment to 'cure' my 'illness'. (Excerpted from his reply to a question)

4). I think acupuncture is...to 'cure' my 'illness'...it is not only the acupuncture to 'cure' my 'illness'. (Excerpted from the final statement)

In this dialogical interaction, Johnson's reuse of words from the textbook is typical type of a repetition that Bakhtin (1986) mentioned that it happens in most of the general conversation when learning a language. In the following dialogue, he begins reshaping, re-evaluating and seeking utterances of appropriateness until they become personalized expressions used in the back and forth communication with the teaching assistant Grace and instructor, as shown in the following excerpt from a voxopop assignment:

Grace: I was scared of many needles entering my body and I could not conquer this fear.

Johnson: When I first got acupuncture, I felt some...fear (he hesitated saying the word "fear") and nervous...

On this occasion, Johnson selected the words used by Grace. More evidences to show that Johnson chose the words on the basis has been used by other speakers. When he replied to a question from the instructor, he used "essential item" rather than accreditation. Nonetheless, he used this term later in his concluding sentence.

Instructor: ... One more question: When you went to see the acupuncturists, did they have accreditation?

Johnson: If I go to see an acupuncturist, I will see some essential item...if I go to see the acupuncture...I will see her all accreditation to decide ...

It appears that Johnson was learning to make new utterances through engagement with others in this learning environment. 


\subsection{Description of Individuals-Brandy's Co-consturction of Utterances}

\subsubsection{On-site Class Dialogue: Brandy}

During the first semester, Brandy partnered with her best friend used the discussion strategies from the textbook. During the second semester, she spent time writing down her answers in case someone asked her a question. During the in-class speaking activities, she used words from the textbook, but still addressed the classmates with whom she was familiar.

\subsubsection{Voxopop Dialogue: Brandy}

During the voxopop activity, Brandy reported that voxopop opinion sharing assignment gave her ideas to share with others from listening to others. In the excepted interview, she said:

I think I got a lot help from opinion sharing because when I listened to others I understand what they're saying and get different ideas and the words that they used and in that way I learned a lot from voxopop."

The following quote shows that Brandy listened from Alice ideas and put into her final statement in the Unit 3 voxopop opinion sharing assignment:

Brandy (Final Statement): After sharing and listened to others opinion, I didn't change my opinion. I think if we banned violent cartoon but we can't ban the news which report about violent. So, we can't prohibit children to keep on violent. I have the same way. The parents should accompany children to watch cartoon, movies and news and teach them what's wrong and what shouldn't do...tell them the reasons and make them have a kind heart. I also like the way that Alice shared with me. She said: "Education is a way to teach children." I really agree with her about the opinion. Everything should change from our life and heart and that can remove the violent.

Brandy tended to include ideas that she heard from others in her replies to Ally. The following dialogue is an excerpt from voxopop, Unit 1 opinion sharing assignment. Brandy got the idea of "buying fridge" from hearing a suggestion from Johnson. She, then used it to answer Ally's question.

Ally: If the person ignores your warning about not taking your food even you told him/her, then he/she still do it over and over again, what would you do? Would you tell him again in a really serious way? Or just don't put your food in the kitchen again?

Brandy: My answer is if he/she takes my food over and over again, I'll try to mark my name on the food plastic bag but if this way can't be work I will not put my food. Not put the food in the kitchen will be a problem, so I think if I will go to buy a small refrigerator and put it in my room and that will solve this problem.

This is a clear illustration of Brandy, adopting a new language form into following interactions with others. Despite the fact that this is not creative or original use of utterance, it is nonetheless a viable approach to the development of speech communication.

In the following section, we seek an answer to the second research question to introduce Johnson and Brandy's initial, developing and final perceptions and attitudes linked to how two EFL college students perceived dialogic activities impact on their utterances development.

Research Question 2: How do EFL college students perceived the effectiveness of oral dialogical activities with regard to their development in learning utterances?

\subsection{Description of Individuals—Johnson's Perception towards Dialogical Activites}

\subsubsection{Initial Perceptions and Attitudes: Prior Awareness}

In the pre-oral reading questionnaire, Johnson reported the he enjoyed reading out loud. Nonetheless, but sometimes he mispronounces words and does not consider himself a good reader. He understood that oral reading is an important skill; however, he described feeling nervous about reading in front of the class. In responding to the pre-speaking questionnaire, Johnson does not like speaking, and he felt nervous when speaking in front of an audience because the difficult part is communicating with others, but pronounce the word is an easy thing. Despite having a had a good experience learning English in senior high school (having won a prize for public speaking), his one experience speaking with an American did not turn out so well, and left a bad impression. Overall, he did not rate himself as a good speaker.

\subsubsection{Developing Perceptions and Attitudes: Learning from Dialogical Activities}

During the course, Johnson claimed that he was a "lazy student, but appreciated that the instructor provided activities." In the voxopop oral reading and speaking (opinion sharing) survey, Johnson reported that he 
"always" perceived oral reading helped to improve his speaking and gave him confidence. He also expressed gratitude he was able to improve his pronunciation. He also reported that listening to others helped him to generate ideas and thoughts and that he "often" enjoyed using the strategies he learned in class. He claimed that the course helped him considerably in improving his speaking. One excerpt from the interview is as follows:

I think opinion sharing activity is the most rewarding experience to me because there are a lot of ideas come in and made me to think of how to respond those questions and so I integrated those ideas and used the discussion strategies to generate my new idea in order to express my own opinion.

While using the voxopop voice board, Johnson occasionally had trouble finding the language forms to suit the situation. As for the oral reading, he made the following statement: "Before recording my oral reading, I usually reviewed the new vocabulary first and then I looked the text over." In the interview, he said, "I only use the vocabulary if I understand or feel familiar with the text." Moreover, Johnson did not use many of the words when recording the voxopop or when engaged in on-site group discussions. This indicates that Johnson probably knew the new vocabulary but did not understand them or feel confident in using them in appropriate manners. Halfway through the year, Johnson would occasionally write down the entire transcript. He said, "I didn't have the transcripts with me when I recorded. However, I would re-record it about 5-6 times and took me about one to two hours for a unit until I feel satisfied." This implies that Johnson would deal with difficulties when he encountered them.

\subsubsection{Final Perceptions and Attitudes: Extent of Change in Development of Utterances}

Two speaking common tests were held in the middle and end of the year. These were used to assess the improvements made by students during the period. The first test was based on the following question: "Do you think you have any of the attributes of an introverted person? Explain." In his monologue, Johnson described himself as a shy person. He presented one example of situation in which someone visited his home when he was young. He did not provide detailed information characterizing himself as a shy person. The monologue was meant to last 90 seconds; however, 30 seconds were spent in silence, thinking of an answer. The second test was based on the following question: "It has been proposed that a new domestic airport should be built quite close to where you live. Do you support or oppose the idea?" In his monologue, Johnson said that he supported the idea and was able to give two reasons: convenience and economic renewal through investment. He spoke for appropriately two minutes with some hesitation but his pronunciation was reasonable and he appeared confident when expressing his ideas. It appears that the practice he had communicating with classmates helped him considerably with regard to generating thoughts and expressing himself. In the following interview, Johnson perceived that he felt a substantial improvement in his speaking ability:

Actually, I feel that speaking with native speakers is not a scary thing after I practiced on the voxopop and I also I feel my mind has been opened, not shy anymore. In addition, I feel confident about my speaking, I remember when I was in freshman and junior was not that confident. I feel my speaking is getting fluency even though I know still have some hesitation, but I know what I'm speaking.

Since participating in this course, Johnson has changed the way he sees the process of learning: "Learning is expanding our view, expanding our knowledge. I think it's like we can know the whole world but, not limited by the space." Clearly, Johnson believes that knowledge is not restricted to books, and can be gained most effectively through interaction with others.

\subsection{Description of Individuals - Brandy's Perception towards Dialogical Activites}

\subsubsection{Initial Perceptions and Attitudes: Prior Awareness}

According to the pre-oral reading questionnaire, Brandy noted that she likes to read, but reads slowly and never mispronounces words. So, she thought she is a good reader. She perceived that oral reading is important and she doesn't feel nervous when reading out loud in front of the class. In responding to the pre-speaking questionnaire, Brandy does not like speaking, and the difficult part is forgetting the words that she was trying to express in front of her audience even though she had fully prepared. That was the most embarrassing moment for her. Overall, she claimed herself as not a good speaker.

\subsubsection{Developing Perceptions and Attitudes: Learning from Dialogical Activities}

At the beginning of dialogic activities, Brandy said about the interview, "I feel annoying for using voxopop, but after I used it I realized that is a good tool for practicing my English because I didn't have much time to speak English in daily life". During the middle year of oral reading voxopop dialogic activities, she perceived oral reading to improve her to learn the way of speaking. She said, "I usually review the new vocabulary first, and sometimes re-recorded the pronunciation of new vocabulary". However, she wasn't thinking that the oral reading 
would help her speaking before taking the course, but now she always feels that oral reading helps her fluency of speaking. However, in the opinion sharing voxopop, she sometimes felt a struggle to get the point across because she always had trouble with the kind of language to suit the situation because "I only used the words in the column from the textbook". Moreover, she was willing to teach the pronunciations with others and is eager to communicate with others after learning from the course. During the middle year of dialogic activities, she did not feel confident about her speaking. However, she perceived that her speaking had improved a lot at the end of the second semester. She said it in the excerpted interview,

I think opinion sharing activity is the most rewarding experience to me because some of the ideas that I never thought of it and the classmate mentioned it then I thought that's really good way to know others and also I can adopt those ideas into my own opinion. In addition, I feel that I'm more confident to ask a question and to respond the question and express my ideas clearly.

Even though she is confident on her speaking, she often wrote down the transcript to complete the recording. In the interview, she said,

In the 1st and 2nd semester, I wrote down the sentences before recording for my statement because I've tried to record it but often not reach the limit of time, so I wrote the words down and so I could expand the time and made recording completeness. But, I didn't write down the transcription when I replied the questions because it was short so I just think though it and then ready to record but it looked like not complete. However, in my opinion, the one without transcriptions would help me to improve my speaking ability and will have a good communication with the native speakers. Even I know this truth, but I still need to write down the words because there are some empty when I recording and I considered that is incompleteness.

This implies that Brandy believes language is written. She perceived that writing down the words will give her the guarantee of the appropriate speaking manner when communicating with others. From here we can see that, language learners are tended to write down all the words when speaking because they believe language is written and that's how they think it's correct and true language because the written format is everywhere. For instance, the classroom language practice is focused on reading and writing and that's why the learners associated those written format is corrected and used in an appropriate place as they think and the only help they can rely on is from the written language (Dufva \& Alanen, 2005).

\subsubsection{Final Perceptions and Attitudes: Extent of Change in Development of Utterances}

Regarding the first common test, the question Brandy was given to answer was: "The government has a right to restrict violence and offensive material in books, movies, and music in order to protect society from violence and criminal behavior. Do you agree or disagree?" In this monologue, she explained what she disagreed. Her opinion was that the government should not have a right to restrict violence because children can access all the materials from everywhere. However, she seemed to drift some away from the point of this question. In the whole statement, she seemed to have confidence about her pronunciation and tried to find words to suit the question. According to the second common test, Brandy received the same question as Johnson. She disagreed, explaining that the airport should not be built near her house even though she pointed out the convenience it will bring because she is not a deep sleeper. However, that was her only reason against it even though she said there are more disadvantages than advantages. But, she did not address more detailed information.

Comparing these two common tests, the results seem to look the same and there are not many differences. In the following interview, Brandy was perceived to have improved a lot in the dialogical activities. She said: "Yes, I do feel I'm more confident and I understand that when I get to know the topic well then I'm easy to express my opinion with others and ask others". This could imply that Brandy is paying attention to those ideas being exchanged even though she cannot deploy those words clearly or which may or may not assist her learning but may help to think logically and prepare her for learn to speak. The final thought for Brandy's perception toward learning after experienced dialogical learning environment, she said, "Learning is getting to know the textbook and unknown things; I also think we can learn from interacting with others." In this excerpted interview, Brandy believed knowledge is in textbooks and is written, therefore, she is able to understand textbooks through interacting with others.

\section{Discussion}

In Bakhtin's view, dialogue is a continual interaction with others by sharing ideas and exchanging words. That is how truth has been born "between people" and that is what Bakhtin called "the process of their dialogic interaction" (Bakhtin, 1984, p. 110). What he means is speaking with others helps the learners to expand their knowledge and perspectives to share important things and learn new utterances. Moreover, the learners need to 
be active learners, seeking chances to communicate with others and being willing to participate in any shared activities. In other words, Bakhtin's model of dialogue is the formation of actively understanding another person and culture (Marchenkova, 2004). Our theoretical argument is that dialogical activities serve the function of developing utterances of learning a foreign language. In this course, Johnson's activeness toward these dialogical activities affected how his utterances change occurred. At the beginning, Johnson was not an active student. For instance, he did not ask for clarification when he did not understand the question, and did not want to ask questions of a person with which he was not familiar. However, by listening to others when recording in voxopop during the second semester, he realized there were some ideas that he never thought about. According to Murray (1999), the voice board is a dialogic activity to create a learning structure which enables learners to make decisions or learn utterances by engaging with others. Also, the voice board enables the learner to proceed according to their pace and ability. They can stop repeating and help the learners make a link between the text and interaction with others so they can have a chance to build up their utterance by listening and repeating to others' dialogue in order to know the words which should be used in an appropriate context. This kind of back and forth repeating is the way of engaging with others. Consequently, when Johnson experienced the dialogue situation from the voxopop and on-site classroom helped him to get focused and understood the new utterances. This attentive and dialogical practice way encourage Johnson that he felt he was engaged in the voxopop and using the language. Furthermore, Johnson tried to use the words by listening and interacting with others in order to practice the words and then later to explain the meaning of words and create his own utterances. Finally, he used the correct words to express his meaning on his own when interacting with the assistant, Grace. From this we can see that, the meaning of utterances can change over as speakers listen to others and will change their usage over time.

Brandy, on the other hand, from the beginning to the end of on-site and voice board activities, often interacted with the people that she was familiar with. During the voxopop dialogical activities, she insisted in writing down the words before recording them because she believed that good language use should be learned and accurately used from the textbook even though she considered that speaking without transcription would be a good way to develop and learning new utterances. Consequently, she failed to use the language and was not engaged in the dialogical activities fully. However, there is one interesting thing to notice that, Brandy was able to make a link between others in order to convey her ideas in a persuasively way when interacted with Johnson during the course. Here we can see that is what Bakhtin (1980) calls the perpetual "link in a very complexly organized chained of other utterances." In short, EFL choose words or ideas based on what they have heard from other speakers on similar and particular occasions to learn and develop utterances. Therefore, when EFL immersing in dialogical learning environment more, then the more chances to learn utterances would be developed in speech communication.

The goal of creating dialogic learning environment is to help participants to strive to develop their utterances in speech communication. However, the participants' activeness affected their outcome of learning utterances. In this course, these two participants provide obvious examples of such differences. According to Hall, Marchenkova and Vitanova (2004), learning a language does not mean to accumulate vocabulary and grammatical rules, but to communicate with others. The more chances we get to interact with others, the more utterances we get to know in order to use in appropriate situation by ourselves. Therefore, the one common thing that happened between these two EFLs was that they do not find the appropriate words in their speech communication. In the course, they didn't use the listed words from the textbook often because they thought those words couldn't fit in their speech context individually. Consequently, EFLs were found to struggle with these words appropriately but, without losing their meaning. This means the utterances that EFLs selected is based on their knowledge and experiences. So, creating a more specific dialogical learning activity in order to help EFLs to evaluate, apply, and make the utterances on their our own later, enrich their ability to understand and be able to participate actively in this speech communication. Therefore, understanding the mental process of the learner and the strategies that he/she uses are acknowledged as important factors because acquiring language needs to be socially intertwined with others by using multiple practices in a variety of contexts (Marchenkova, 2004).

These results evidenced that educators need to attend to and focus more on the development of learning utterances of language to help students in speech communication. An important instructional implication of this study is that we are better able to understand when language learners understand the words of meaning does not relate that the learners are able to use the actual language in the particular situations. Therefore, the actual purpose of developing utterances in the learning of a foreign language is giving the EFL a dialogical learning environment to interact with others. At this point in time, the dialogical activities with voxopop voice board have 
been shown to facilitate developing language utterances. According to Bygate (2006), giving L2 learners more time to modify their expressions not only correct the accuracy but also providing them alternative way for looking at appropriate situation and manner. Therefore, the on-site class and voxopop voice board have been done in this study is because the L2 learners are often focused on the content and try to find the words to express their opinions but not in an appropriate context. Consequently, when EFLs involve in the on-site class and voxopop voice board which provide them to think of more expressions and expressing alternatives of their ideas in a dialogical learning environment. Moreover, we need to take this perspective to offer opportunities for the EFL students to engage in what Bakhtin (1986) called the dialogism, as discussed above. Accordingly, instructors can create opportunities to promote students' awareness of dialogically constructed their own and others with whom they will interact in social environment and discourses.

\section{Acknowledgments}

We would like to show our gratitude to the two participants for sharing their thoughts with us during the course of this research that greatly assisted the research.

\section{References}

Alanen, R. (2006). A Sociocultural Approach to Young Language Learners' Belief about Language Learning. In P. Kalaja, \& A. Barcelos (Eds.), Beliefs about SLA (pp. 55-85). Netherlands: Springer.

Bakhtin, M. M. (1986). The problem of speech genres. In C. Emerson, \& M. Holquist (Eds.), Speech genres and other late essays (pp. 60-102). Austin: University of Texas Press.

Baralt, M., \& Gurzynski-Weiss, L. (2011). Comparing learners' state anxiety during task-based interaction in computer-mediated and face-to-face communication. Language Teaching Research, 15(2), 201-229. http://dx.doi.org/10.1177/0265532210388717

Bygate, M. (2006). Areas of research that influence L2 speaking instruction. In E. Uso-Juan, \& A. Martinez-Flor (Eds.), Current trends in the development and teaching of the four language skills. (pp. 159-186). Berlin: Mouton de Gruyter.

Collings, N. (2007). Foreign language in a dialogue and monologue with culture: A case study of one foreign language classroom from Bakhtinian and Vygotskian perspectives. VDM Verlag Dr. Müller, Saarbrücken.

Dufva, H. (2006). Beliefs in Dialogue: A Bakhtinian View. In P. Kalaja, \& A. Barcelos (Eds.), Beliefs about SLA (pp. 131-151). Netherlands: Springer.

Dufva, H., \& Alanen, R. (2005). Metalinguistic awareness in dialogue: Bakhtinian considerations. In J. K. Hell, G. Vitanova, \& L. Marchenkova (Eds.) Dialogue with Bakhtin on second and foreign language learning. (pp. 99-118). Mahwah, NJ: Lawrence Erlbaum Associates.

Hall, J. K., Marchenkova, L. A., \& Vitanova, G. (2004). Introduction: Dialogue with Bakhtin on second and foreign language learning. In J. K., Hall, L. A. Marchenkova, \& G. Vitanova (Eds.), Dialogue With Bakhtin on Second and Foreign Language Learning: New Perspectives (pp. 1-8). Mahwah: Lawrence Erlbaum Associates. http://dx.doi.org/10.1145/971258.971270

Hosenfeld, C. (2006). Evidence of Emergent Beliefs of a Second Language Learner: A Case Study. In P. Kalaja, \& A. Barcelos (Eds.), Beliefs about SLA (pp. 37-54). Netherlands: Springer.

Hsu, H. Y., Wang, S. W., \& Comac, L. (2008). Using audio-blogs to assist English-language learning: An investigation into student perception, Computer Assisted Language Learning, 21(2), 181-198.

Marchenkova, L. A. (2004). Language, culture, and self: The Bakhtin-Vygotsky encounter. In J. K. Hall, L. A. Marchenkova, \& G. Vitanova (Eds.), Dialogue with Bakhtin on Second and Foreign Language Learning: New Perspectives (pp. 171-188). Mahwah: Lawrence Erlbaum Associates.

Mercer, N. (1995) The Guided Construction of Knowledge: Talk amongst teachers and learners. Clevedon: Multilingual Matters.

Murray, G. L. (1999). Autonomy and Language Learning in a Simulated Environment. System: An International Journal of Educational Technology and Applied Linguistics, 27(3), 295-308. http://dx.doi.org/10.1016/S0346-251X(99)00026-3

Özdener, N., \& Satar, H. M. (2008). Computer-Mediated Communication in Foreign Language Education: Use of Target Language and Learner Perceptions. Journal of Distance Education-TOJDE, 9(2). 
Pavlenko, A., \& Lantolf, J. P. (2000). Second language learning as participation and the (re)construction of selves. Sociocultural Theory and Second Language Learning (pp. 155-177). Oxford: Oxford University Press.

Pop, A., Tomuletiu, E. A., \& David, D. (2011). EFL speaking communication with asynchronous voice tools for adult students. Procedia - Social and Behavioral Sciences, 15(0), 1199-1203. http://dx.doi.org/10.1016/j.sbspro.2011.03.262

Tallon, M. (2009). Foreign language anxiety and heritage students of Spanish: A quantitative study. Foreign Language Annals, 42(1), 112-137. http://dx.doi.org/10.1111/j.1944-9720.2009.01011.x

Valle, J. W., \& Aponte, E. (2002). IDEA and collaboration: A Bakhtinian perspective on parent and professional discourse. Journal of Learning Disabilities, 351 35(5), http://dx.doi.org/10.1177/00222194020350050701

Van Lier, L. (2000). From input to affordance: Social-interactive learning from an ecological perspective. Sociocultural Theory and Second Language Learning (pp. 155-177). Oxford: Oxford University Press.

Vygotsky, L. S. (1978). Mind in society: The development of higher psychological processes. Cambridge, MA: Harvard University Press.

Wertsch, J. V., Hagstrom, F., \& Kikas, E. (1995). Voices of thinking and speaking. In L. M. W. Martin, K. Nelson, \& E. Tobach (Eds.), Sociocultural psychology: Theory and practice of doing and knowing. (pp. 276-290). Cambridge: Cambridge University Press.

\section{Appendix}

\section{Oral Class Interview Questions}

1). What is learning?

2). What benefits you from the class?

3). Have you ever experienced confusing or misunderstanding from the course teaching and voxopop recording? If you did, what did you do to clear?

4). What do you feel when you were in the class and voxopop? Are there any differences?

5). Do you learn any words or expression from others and teachers? What impressed you? What about oral reading? Does it help you to understand the words and talk in practice with voxopop?

6). Do you see ourselves getting to know how to speak? How does voxopop help you to talk or not?

7). Do you think you get improved by taking this course or from the voxopop?

8). What did you do when you were not able to speak in a word or sentence?

9). How do you see the class discussion, voxopop recordings gave or made you confident on your writing and speaking?

\section{Copyrights}

Copyright for this article is retained by the author(s), with first publication rights granted to the journal.

This is an open-access article distributed under the terms and conditions of the Creative Commons Attribution license (http://creativecommons.org/licenses/by/3.0/). 